\title{
Cytokine concentrations in seminal plasma from subfertile men are not indicative of the presence of Ureaplasma urealyticum or Mycoplasma hominis in the lower genital tract
}

\author{
YVONNE PANNEKOEK, JOHANNES W. TRUM*, OTTO P. BLEKER $\dagger$, FULCO VAN DER VEEN*, \\ LODEWIJK SPANJAARD and JACOB DANKERT
}

\begin{abstract}
Department of Medical Microbiology, * Center for Reproductive Medicine, Department of Obstetrics and Gynecology and †Department of Obstetrics and Gynecology, Academic Medical Center, Amsterdam, The Netherlands
\end{abstract}

\begin{abstract}
The inflammatory response to the presence of Ureaplasma urealyticum or Mycoplasma hominis in the lower genital tract of subfertile men without any signs or symptoms of infection was investigated by measuring the concentrations of interleukin (IL)-6, IL-8, tumour necrosis factor- $\alpha$ (TNF- $\alpha$ ) and interferon- $\gamma$ (IFN- $\gamma$ ) in seminal plasma. Semen samples were collected from 30 culture-positive subfertile males and 23 culture-negative subfertile males. Enzyme-linked immunosorbent assays showed that IL-8 was present in relatively high concentrations $(0.12-4.8 \mathrm{ng} / \mathrm{ml})$ in all semen samples investigated. In contrast, the other cytokines were only detectable in $72 \%$ (IFN- $\gamma$ ), 44\% (IL-6) and 19\% $(\mathrm{TNF}-\alpha)$ of the samples and were present in relatively low concentrations $(1-410 \mathrm{pg} / \mathrm{ml})$. Seminal plasma cytokine concentrations were similar in samples from culture-positive and culture-negative males. These data strongly indicate that the presence of $U$. urealyticum or $M$. hominis in the lower genital tract of subfertile males reflects a silent colonisation rather than infection.
\end{abstract}

\section{Introduction}

Mycoplasmas are a unique group of bacteria, characterised by their small cell size $(0.3-0.8 \mu \mathrm{m})$, small genome size and lack of a rigid bacterial cell wall [1]. Among the 16 species that have been isolated from man, Mycoplasma hominis and Ureaplasma urealyticum are frequently cultured from the lower genital tract with reported incidences of 5-30\% for M. hominis and $30-85 \%$ for $U$. urealyticum [2-5].

Several studies in women have indicated that vaginal colonisation with $U$. urealyticum or M. hominis can be associated with an increased risk of developing bacterial vaginosis, pelvic inflammatory disease and post-partum septicaemia. Premature rupture of membranes and preterm labour and birth have also been associated with these bacteria [6-10]. However, the presence of both genital mycoplasmas in a large

Received 10 Dec. 1999; accepted 24 Dec. 1999.

Corresponding author: Dr Y. Pannekoek (e-mail: y.pannekoek@amc.uva.nl). proportion of healthy women complicates the assessment of the pathogenic role of these organisms [10].

The pathogenic role of M. hominis and U. urealyticum in men is still less clear than in women. It has been proposed that $M$. hominis could have a role in the onset of non-gonococcal urethritis (NGU), but its sole presence can be considered as commensal [10]. $U$. urealyticum has been isolated from males with primary and recurrent NGU, but whether a pathological condition can be attributed solely to this species is difficult to determine, as $U$. urealyticum can be cultured from the lower genital tract in a high proportion of asymptomatic males $[4,5]$.

The presence of $U$. urealyticum or M. hominis in the lower genital tract of subfertile men, in the absence of any other bacterial pathogen, may reflect a silent colonisation rather than infection.

Inflammatory mediators - interleukin (IL)-6, IL-8, tumour necrosis factor- $\alpha$ (TNF- $\alpha$ ) and interferon- $\gamma$ $(\mathrm{IFN}-\gamma)-$ mediate the host immune response that accompanies infection [11]. Therefore, the present 
study determined the levels IL-6, IL-8, TNF- $\alpha$ and IFN- $\gamma$ in seminal plasma from mycoplasma culturepositive and culture-negative subfertile men.

\section{Materials and methods}

\section{Study population}

The study population consisted of 53 subfertile men attending the Center for Reproductive Medicine at this hospital. They were selected from a larger group $(\mathrm{n}=184)$ participating in a study evaluating sexually transmitted disease as a cause of male subfertility [5]. Permission to conduct this study was obtained from the hospital's institutional review board and all subjects gave their consent to participate [5].

\section{Selection criteria}

Bacterial culture of urethral swabs, taken after digital prostatic massage, was performed according to standard methods as described previously [5]. Semen samples from 24 men, whose urethral swab culture showed the presence of $U$. urealyticum only, and six semen samples, from men with only a $M$. hominis culturepositive urethral swab were selected. Semen samples from 23 men, who were culture-negative for all bacteria tested (U. urealyticum, M. hominis, Neisseria gonorrhoeae and Chlamydia trachomatis) were included as controls. None of these 53 men had any signs or symptoms of infection.

\section{Cytokine measurements}

Semen was collected by masturbation after at least $72 \mathrm{~h}$ of abstinence, liquefied and centrifuged at $1000 \mathrm{~g}$ for $10 \mathrm{~min}$ to remove cells and debris. The seminal plasma was aspirated and stored at $-80^{\circ} \mathrm{C}$. Levels of IL-6, IL-8, TNF- $\alpha$ and IFN- $\gamma$ were measured by Pelikine-Compact enzyme-linked immunosorbent assays (ELISAs), according to the manufacturer's instructions (Central Laboratory of the Netherlands Red Cross Blood Transfusion Service, Amsterdam, The Netherlands). Briefly, semen samples were added to the wells of microtitration plates pre-coated with anti-cytokine mouse monoclonal antibodies. After incubation at room temperature for $1 \mathrm{~h}$, the unbound components were removed by washing. Second antihuman cytokine biotin-conjugated antibodies were added and incubated for $1 \mathrm{~h}$ at room temperature. After washing of the wells, streptavidin-horseradish peroxidase (polyconjugated) was added and incubated for $30 \mathrm{~min}$ at room temperature. Finally, substrate was added, colour was developed for $15 \mathrm{~min}$ and the reaction was stopped with stop solution. Absorbance was measured at $450 \mathrm{~nm}$ with an ELISA reader. Samples were assayed twice in duplicate. Individual levels are expressed as means, group levels as medians and ranges.

\section{Statistical analysis}

Differences in the levels of IL-6, IL-8, TNF- $\alpha$ and IFN- $\gamma$ between patients with and without a positive culture for mycoplasmas were assessed by the nonparametric test (Mann Whitney U test, Wilcoxon Rank Sum $\mathrm{W}$ test). Values of $\mathrm{p}<0.05$ were considered significant.

\section{Results}

A total of 53 semen samples was available for cytokine analysis. These samples were derived from 53 men of whom 24 were culture-positive for $U$. urealyticum and six were culture-positive for $M$. hominis. No subjects were positive for $N$. gonorrhoeae or $C$. trachomatis. The remaining 23 samples, obtained from males who tested negative for U. urealyticum, M. hominis, $N$. gonorrhoeae and $C$. trachomatis, served as culturenegative controls.

Analysis of cytokines by ELISA indicated that IL-8 was present in all samples tested. In contrast, IFN- $\gamma$ was found in $38(72 \%)$ samples, IL-6 in $24(44 \%)$ and TNF- $\alpha$ in only 10 (19\%) samples (Fig. 1). IL-8 was present in relatively high concentrations, ranging from 0.12 to $4.8 \mathrm{ng} / \mathrm{ml}$. The levels of the other three cytokines investigated were low, ranging from 1 to $410 \mathrm{pg} / \mathrm{ml}$ (Table 1).

Seminal concentrations of the four cytokines assayed (IL-6, IL-8, TNF- $\alpha$ and IFN- $\gamma$ ) in the culture-positive and -negative group were not different from each other $(\mathrm{p}>0.05)$ (Table 1).

\section{Discussion}

Numerous studies clearly indicate that mycoplasmas are able to modulate the activities of various immune cells, and thus trigger the production of a wide variety of inflammatory and anti-inflammatory cytokines [1]. However, data on such modulating activities when $U$. urealyticum and M. hominis are present in the genital tract are sparse [1].

The aim of the present study was to investigate whether the presence of $U$. urealyticum or M. hominis in the lower genital tract of subfertile men is associated with infection, as indicated by elevated levels of cytokines due to the inflammatory response. The data showed that there were no differences in the levels of the four cytokines investigated (IL-6, IL-8, TNF- $\alpha$ and IFN- $\gamma$ ) in mycoplasma culture-positive and -negative men.

Elevated concentrations of cytokines (including IL-6 and IL-8) measured in seminal plasma from infertile men have been related to the presence of various bacterial species in the male genital tract [12-15]. In 

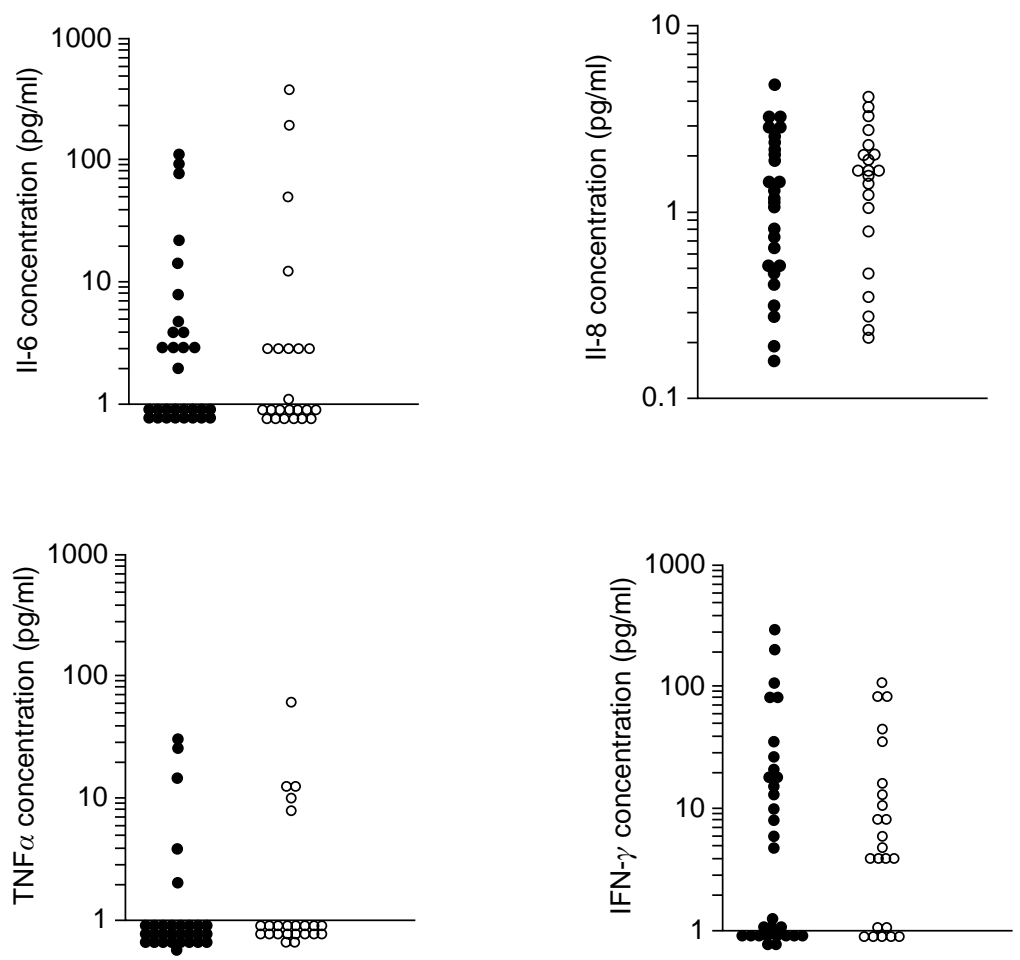

Fig. 1. Individual seminal plasma concentrations of IL-6, IL-8, TNF- $\alpha$ and IFN- $\gamma$ in mycoplasma culture-positive and culture-negative $(O)$ subfertile men. Data are expressed as the mean value of two independent assays.

Table 1. Cytokine levels in seminal plasma of U. urealyticum or M. hominis culture-positive and culture-negative subfertile men

\begin{tabular}{lccccc}
\hline & & \multicolumn{4}{c}{ Median (range) } \\
\cline { 2 - 6 } $\begin{array}{l}\text { U. urealyticum } \\
\text { or M. hominis }\end{array}$ & $\mathrm{n}$ & $\begin{array}{c}\mathrm{IL}-8 \\
(\mathrm{ng} / \mathrm{ml})\end{array}$ & $\begin{array}{c}\mathrm{IL}-6 \\
(\mathrm{pg} / \mathrm{ml})\end{array}$ & $\begin{array}{c}\mathrm{TNF}-\alpha \\
(\mathrm{pg} / \mathrm{ml})\end{array}$ & $\begin{array}{c}\mathrm{IFN}-\gamma \\
(\mathrm{pg} / \mathrm{ml})\end{array}$ \\
\hline Culture positive & 30 & 1.05 & 0 & 0 & 5.5 \\
& & $(0.16-4.7)$ & $(0-103)$ & $(0-29)$ & $(0-280)$ \\
Culture negative & 23 & 1.52 & 0 & 0 & 5.5 \\
& & $(0.12-3.6)$ & $(0-410)$ & $(0-76)$ & $(0-100)$ \\
\hline
\end{tabular}

contrast, other investigators found no differences in levels of IL-6, IL-8 and TNF- $\alpha$ between culturepositive and -negative infertile men [16-18]. Direct comparison of these data with the findings of the present study is difficult, because infertile men were investigated in the former study, whereas the present study included subfertile men. Furthermore, none of these studies analysed the single contribution of $U$. urealyticum and M. hominis to cytokine levels. As the present study included only men with either a $U$. urealyticum or a M. hominis positive culture and found no marked differences in the cytokine levels between this group and the culture-negative control group, this is the first direct demonstration that the single presence of either $U$. urealyticum or $M$. hominis is not associated with elevated levels of IL-6, IL-8, TNF- $\alpha$ and IFN- $\gamma$ in semen.

An earlier study demonstrated that the presence of high numbers $\left(>1 \times 10^{6} / \mathrm{ml}\right)$ of leucocytes in semen of subfertile men (leucocytospermia), a phenomenon suggesting inflammation, was not related to the presence of $U$. urealyticum or M. hominis, which also indicates that these bacteria are not associated with an inflammatory response due to infection [5]. This finding, in conjunction with the absence of any difference in the levels of the four inflammatory indicators assayed, and the complete absence of signs and symptoms of genital tract infection, strongly points to the view that no pathological role can be attributed to these bacteria and that their presence in the lower genital tract reflects a silent colonisation.

However, the question arises as to whether isolation of $U$. urealyticum or $M$. hominis from urethral swab cultures of subfertile men can be ignored. Isolation of these bacteria remains important, as they are sexually transmitted and can be associated with an increased risk of pathogenic conditions and pregnancy abnormalities in women [10]. In the light of the results of the present study, the pathogenic role of these bacteria in male genital tract disease remains questionable. 


\section{References}

1. Razin S, Yogev D, Naot Y. Molecular biology and pathogenicity of mycoplasmas. Microbiol Mol Biol Rev 1998; 62 1094-1156.

2. Samra Z, Soffer Y, Pansky M. Prevalence of genital chlamydia and mycoplasma infection in couples attending a male infertility clinic. Eur J Epidemiol 1994; 10: 69-73.

3. Soffer Y, Ron-El R, Golan A, Herman A, Caspi E, Samra Z. Male genital mycoplasmas and Chlamydia trachomatis culture: its relationship with accessory gland function, sperm quality, and autoimmunity. Fertil Steril 1990; 53: 331-336.

4. Moskowitz MO, Mellinger BC. Sexually transmitted diseases and their relation to male infertility. Urol Clin North Am 1992; 19: $35-45$.

5. Trum JW, Mol BWJ, Pannekoek Y et al. Value of detecting leukocytospermia in the diagnosis of genital tract infection in subfertile men. Fertil Steril 1998; 70: 315-319.

6. Hill GB. Preterm birth: associations with genital and possibly oral microflora. Ann Periodontol 1998; 3: 222-232.

7. Holst E, Goffeng AR, Andersch B. Bacterial vaginosis and vaginal microorganisms in idiopathic premature labor and association with pregnancy outcome. J Clin Microbiol 1994; 32: $176-186$

8. Krohn MA, Hillier SL, Nugent RP et al. The genital flora of women with intraamniotic infection. J Infect Dis 1995; 171: $1475-1480$

9. McDonald HM, O’Loughlin JA, Jolley PT, Vigneswaran R, McDonald PJ. Changes in vaginal flora during pregnancy and association with preterm birth. $J$ Infect Dis 1994; 170:
$724-728$.

10. Taylor-Robinson D, Furr PM. Update on sexually transmitted mycoplasmas. Lancet 1998; 351 Suppl 3: 12-15.

11. Lucey DR, Clerici M, Shearer GM. Type 1 and type 2 cytokine dysregulation in human infectious, neoplastic, and inflammatory diseases. Clin Microbiol Rev 1996; 9: 532-562.

12. Comhaire F, Bosmans E, Ombelet W, Punjabi U, Schoonjans F. Cytokines in semen of normal men and of patients with andrological diseases. Am $J$ Reprod Immunol 1994; 31: 99-103.

13. Depuydt CE, Bosmans E, Zalata A, Schoonjans F, Comhaire $\mathrm{FH}$. The relation between reactive oxygen species and cytokines in andrological patients with or without male accessory gland infection. J Androl 1996; 17: 699-707.

14. Koumantakis E, Matalliotakis I, Kyriakou D, Fragouli Y, Relakis K. Increased levels of interleukin-8 in human seminal plasma. Andrologia 1998; 30: 339-343

15. Matalliotakis I, Kiriakou D, Fragouli I, Sifakis S, Eliopoulos G, Koumantakis E. Interleukin-6 in seminal plasma of fertile and infertile men. Arch Androl 1998; 41: 43-50.

16. Dousset B, Hussenet F, Daudin M, Bujan L, Foliguet B, Nabet P. Seminal cytokine concentrations (IL-1beta, IL-2, IL-6, sR IL-2, sR IL- 6), semen parameters and blood hormonal status in male infertility. Hum Reprod 1997; 12: 1476-1479.

17. Huleihel M, Lunenfeld E, Levy A, Potashnik G, Glezerman M. Distinct expression levels of cytokines and soluble cytokine receptors in seminal plasma of fertile and infertile men. Fertil Steril 1996; 66: 135-139.

18. Hussenet F, Dousset B, Cordonnier JL et al. Tumour necrosis factor alpha and interleukin 2 in normal and infected human seminal fluid. Hum Reprod 1993; 8: 409-411. 